\title{
Nasal DNA-MVA SIV vaccination provides more significant protection from progression to AIDS than a similar intramuscular vaccination
}

\author{
M Manrique ${ }^{1,2}$, PA Kozlowski ${ }^{3}$, S-W Wang ${ }^{1,2,6}$, RL Wilson $^{3}$, E Micewicz ${ }^{1,2}$, DC Montefiori ${ }^{4}$, \\ KG Mansfield ${ }^{5}$, A Carville ${ }^{5}$ and A Aldovini ${ }^{1,2}$
}

Preventive human immunodeficiency virus (HIV) vaccination may require induction of virus-specific immune responses at mucosal sites to contain viral infection locally after exposure, as most HIV infections occur through mucosal surfaces. We compared the efficacy of an intranasal or intramuscular Simian immunodeficiency virus (SIV) + interleukin (IL)2+IL-15 DNA/SIV-MVA (modified vaccinia virus Ankara) vaccination in preventing disease progression in SIVmac251 intrarectally challenged rhesus macaques. SIV-specific rectal IgA responses were more significantly persistent in nasally vaccinated than in intramuscularly vaccinated animals. No significant differences were observed in the magnitude of systemic T-cell responses between the two groups, although the nasal immunization induced more significant anti-SIV T-cell responses in the colorectal mucosa. After challenge, $\mathrm{CD} 4^{+}$central memory $\left(\mathrm{C}_{\mathrm{M}}\right) \mathrm{T}$-cell preservation and significant disease-delay were observed in both vaccination groups. However, nasally vaccinated animals had more significant early preservation of circulating and colorectal $C D 4^{+} C_{M}$ T cells, of circulating CD4+/ $\alpha 4 \beta 7^{+}$effector memory $\left(E_{M}\right) T$ cells, and a longer disease-free interval when compared with the intramuscularly vaccinated or control groups. Regardless of vaccination status, long-term viremia control and preservation of $\mathrm{CD} 4{ }^{+} \mathrm{C}_{\mathrm{M}} \mathrm{T}$ cells was detected in animals with significantly higher systemic $\mathrm{CD} 8^{+} /$tumor necrosis factor (TNF)- $\alpha^{+}$and $\mathrm{CD} 8^{+} /$interferon (IFN)- $\gamma^{+} \mathrm{T}$-cell responses and higher SIV-specific CD4 ${ }^{+} / \mathrm{IL}-2^{+}$responses in colorectal T cells.

\section{INTRODUCTION}

Development of a vaccine that can protect from the acquired immunodeficiency syndrome (AIDS) resulting from human immunodeficiency virus type-1 (HIV-1) infection remains a high public health priority worldwide. Several prime-boost strategies involving priming with a DNA vaccine followed by boosting with a live recombinant vector-based vaccine have been tested in monkeys for efficacy against challenge with a lethal dose of simian-human immunodeficiency virus (SHIV). ${ }^{1-6}$ These strategies resulted in significant and long-lasting reduction in virus loads and provided protection against disease and death of the vaccinated animals. Similar approaches were less successful in protection against Simian immunodeficiency virus (SIV) challenge. ${ }^{7-9}$ These vaccines administered intramuscularly (IM) provided a substantially smaller reduction of the viremia and only a temporal protection from $\mathrm{CD} 4^{+} \mathrm{T}$-cell loss that lasted $\sim 6$ to 8 months after challenge with SIV. ${ }^{7,10-12}$ The DNA/live vector approach predominantly stimulates cell-mediated immunity with poor or absent stimulation of systemic and mucosal humoral immunity, ${ }^{12-14}$ including neutralizing antibodies, which have been shown to be critical to the protection provided by other vaccines for viral infections. A HIV-expressing adenovector (HIV-Ad5) approach tested in humans failed to prevent infection and to reduce viral loads in HIV-infected individuals, and it increased HIV-1 infection rates in subgroups of vaccine recipients compared with the controls. ${ }^{15,16}$ Although the results of this clinical trial were very discouraging, it is possible that they might be restricted to a vaccine platform that uses an adenovirus-base

${ }^{1}$ Children's Hospital Boston, Department of Medicine, Harvard Medical School, Boston, Massachusetts, USA. ${ }^{2}$ Department of Pediatrics, Harvard Medical School, Boston, Massachusetts, USA. ${ }^{3}$ Gene Therapy Program, Department of Microbiology, Immunology and Parasitology, Louisiana State University Health Sciences Center, New Orleans, Louisiana, USA. ${ }^{4}$ Department of Medicine, Duke University School of Medicine, Durham, North Carolina, USA. ${ }^{5}$ New England Regional Primate Research

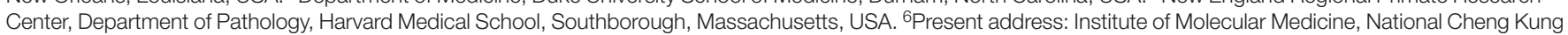
University, College of Medicine, Tainan, Taiwan. Correspondence: A Aldovini (anna.aldovini@childrens.harvard.edu) 
strategy in a population with preexisting adenoviral immunity. Results indicated that vaccine recipients with high levels of antibodies against the Ad5 vector were more likely to acquire HIV infection than those who was given a placebo, and may not apply to other vaccine platforms. ${ }^{15}$ The IM route has been the predominant route used for the delivery of HIV and SIV vaccines in humans and non-human primates. ${ }^{5,6,15,17-19,21}$ Although comparison of vaccine efficacy after administration through different routes exists in the SHIV model ${ }^{22}$ and for the SIV system through two mucosal routes, ${ }^{23}$ no direct comparison of a SIV vaccine administered through a systemic and a mucosal route, followed by mucosal challenge, is available.

As HIV and SIV are mucosal diseases that cause massive loss of mucosal CD4 ${ }^{+}$T-cell central memory $\left(\mathrm{C}_{\mathrm{M}}\right),{ }^{24-30}$ and mucosal vaccination is generally more effective than parenteral vaccination for induction of mucosal immunity, ${ }^{31}$ we reasoned that a mucosal route of immunization may provide better protection than an immunization given systemically. Preference for a mucosal rather than a systemic route of vaccination for disease prevention has an important precedent in the oral Sabin and IM Salk polio vaccines, although an important difference between these two is also the fact that the Sabin vaccine includes a liveattenuated virus, whereas the virus is inactivated in the the Salk vaccine. ${ }^{32,33}$ The goal of this vaccine study was to investigate whether DNA SIV + cytokines prime/SIV rMVA (recombinant modified vaccinia virus Ankara) boost vaccination administered through the nasal $(\mathrm{N})$ route is more effective than the IM route for preventing the decline of the immune system and the appearance of disease symptoms.

\section{RESULTS}

\section{Evaluation of the SIV DNA-MVA immunogenicity after IM or $\mathrm{N}$ immunization}

The aim of this study was to evaluate the level of protection achieved with a DNA/rMVA vaccination and to determine whether an $\mathrm{N}$ vaccination strategy compared favorably with the IM regimen in the SIV model. Two groups of animals were immunized nasally (N group) or IM (IM group) with three doses of SIV DNA and IL-2 and IL-15 DNA, followed by one vaccination with rMVAs expressing Gag, Pol, and Env SIV antigens.

The anti-SIV systemic and mucosal humoral and cellular responses were evaluated during the immunization. Six of the seven animals immunized nasally developed SIV-specific IgA antibodies that could be detected at two or more time points in rectal secretions (Table 1). Anti-SIV IgA antibodies were also detected in the rectal secretions of four of the seven animals in the IM group but at only one time point in three of these four responders (Table 1). The frequency of animals showing

Table 1 SIV-specific IgA antibody in pre-challenge rectal secretions

\begin{tabular}{|c|c|c|c|c|c|c|}
\hline \multirow[b]{2}{*}{ Animal } & \multicolumn{6}{|c|}{ Fold increase in ng anti-SIV gag/pol or anti-gp130 antibody per $\mu \mathrm{g}$ IgA } \\
\hline & Week 11 & Week 13 & Week 29 & Week 33 & Week 35 & Week 41 \\
\hline \multicolumn{7}{|l|}{ Ngroup } \\
\hline 298 & $-1-$ & $-1-$ & $-1-$ & $-1-$ & $-1-$ & $-1-$ \\
\hline $315^{\star}$ & $-1-$ & $-/ 4.6$ & -16.5 & $-1-$ & $-1-$ & $-1-$ \\
\hline 363 & $3.6 /-$ & $-1-$ & $-1-$ & $-1-$ & $-1-$ & $5.9 /-$ \\
\hline 375 & $-1-$ & $-1-$ & $4.3 /-$ & $4.7 /-$ & $-1-$ & $-1-$ \\
\hline 377 & $-/ 6.4$ & $6.0 / 3.5$ & $-/ 10.7$ & $-1-$ & $-1-$ & $-1-$ \\
\hline $386^{*}$ & $-1-$ & $17.6 /-$ & $25.1 /-$ & $36.3 / 3.4$ & $5.2 /-$ & $5.3 /-$ \\
\hline 471 & $-1-$ & $8.9 / 15.0$ & $4.1 / 7.0$ & $7.9 / 23.2$ & $-1-$ & $-1-$ \\
\hline \multicolumn{7}{|c|}{ IM group } \\
\hline $29^{*}$ & $-/ 3.9$ & $-1-$ & $-1-$ & $-1-$ & $-1-$ & $-1-$ \\
\hline 312 & $15.6 / 10.5$ & $-1-$ & $5.5 / 4.7$ & $-1-$ & $-1-$ & $-1-$ \\
\hline 365 & $-1-$ & $-1-$ & $-1-$ & $-1-$ & $-1-$ & $-1-$ \\
\hline 366 & $-1-$ & $-1-$ & $-1-$ & $-1-$ & $-/ 13.7$ & $-1-$ \\
\hline $409^{\star}$ & $-/ 7.9$ & $-1-$ & $-1-$ & $-1-$ & $-1-$ & $-1-$ \\
\hline 435 & $-1-$ & $-1-$ & $-1-$ & $-1-$ & $-1-$ & $-1-$ \\
\hline 446 & $-1-$ & $-1-$ & $-1-$ & $-1-$ & $-1-$ & $-1-$ \\
\hline
\end{tabular}

Increases for SIV lysate and gp130 are shown before and after the slash, respectively.

Secretions were considered positive for anti-SIV IgA Ab when: 1, the specific activity to gp130 or SIV Iysate was $\geqslant 0.145$ or 0.224 , respectively, which represent the mean specific activity +3 s.d. for secretions from naive macaques; 2 , the fold increase (postimmunization/preimmunization) had to be $\geqslant 3.4-$ fold. Only significant (>3.4) fold increases are provided.

Dashes denote the insignificant.

Fold increases were calculated by dividing the post-immunization by the pre-immunization specific activity (ng antibody per $\mu$ g IgA). If no antibody was detected in a pre-immune sample, the post-immunization value was divided by the mean specific activity value previously measured in rectal secretions from 12 naive animals (0.049 for gp130; 0.083 for SIV lysate).

DNA vaccination \#2 and \#3 were on week 9 and week 25. MVA boosting was on week 33.

Asterisks $\left(^{*}\right)$ indicate MamuA*01-positive animals. 
a positive rectal $\operatorname{Ig} \mathrm{A}$ response to either of the SIV antigens at more than one post-vaccination time point was significantly greater in the $\mathrm{N}$ group than in the IM group (6/7 vs. 1/7, respectively; $P=0.0291$ ). By the time of challenge, IgA responses were not detectable in the animals in either vaccination group. The anti-SIV IgA analysis of saliva was carried out with samples collected at 2 and 4 weeks after the third DNA immunization and the rMVA immunization. All these samples were negative. SIVspecific IgG antibodies in rectal secretions were not measured because we and others have found that, in the absence of very strong systemic IgG responses, it is difficult to detect IgG antibodies in rectal secretions of vaccinated macaques. ${ }^{1,2,20}$

Plasma anti-SIV IgG responses were negative in both groups during the DNA vaccination (Figure 1a and $\mathbf{b}$ ). On week 35, 2 weeks after MVA boosting, plasma anti-Gag/Pol IgG titers increased in the IM group but not in the $\mathrm{N}$ group and the titer difference was statistically significant (Figure 1a, $P=8.6 \times 10^{-6}$ ). Similarly, on week 35 and on the day of challenge, the titers of gp130-specific IgG were significantly greater in the IM group than those in the $\mathrm{N}$ group (both $P=0.0017$ ).

Differences in systemic and mucosal T-cell responses were observed in the two immunization regimens (Figure 2). From week 16 to week 45, circulating Gag-specific plus Env-specific $\mathrm{CD}^{+} / \mathrm{IL}^{2}{ }^{+}, \mathrm{CD}^{+} /$interferon (IFN) $-\gamma^{+}$, and $\mathrm{CD} 8^{+} /$tumor necrosis factor (TNF)- $\alpha^{+}$T-cell levels were slightly higher in the IM group compared with those in the $\mathrm{N}$ group, although the difference was not significant (Figure 2a). In contrast, SIVspecific CD $4^{+} / \mathrm{IL}-2^{+} \mathrm{T}$ cells measured in rectal mononuclear cells (MNCs) at weeks 35 and 39 (2 and 4 weeks after MVA boosting) were significantly higher in the $\mathrm{N}$ group than those in the IM group ( $P=0.049$ for week $35, P=0.037$ for week 39, Figure 2b). Significantly higher levels of SIV-specific $\mathrm{CD}^{+} /$ IFN $-\gamma^{+}$T cells were also detected in the rectal biopsies of the $\mathrm{N}$ group compared with IM group at weeks $28(P=0.026)$ and $35(P=0.037), 3$ weeks after the third DNA immunization and the MVA boosting, respectively. These data indicate that, when compared with IM immunization, $\mathrm{N}$ immunization can more efficiently induce specific $\mathrm{T}$ cells in both mucosal and systemic immune compartments.

\section{Challenge and post-challenge virological follow-up}

Starting on week 45, rectal low-dose SIV challenge was administered weekly to all vaccinated animals and six naive controls until plasma samples were positive for SIV RNA. The average number of challenges required for infection of the animals was 4.05 (range 2-11). There was no significant difference between groups in the number of challenges received ( $\mathrm{N}$ group: 3.3; IM group: 5.7; and control group: 3.1 ).

SIV plasma viral loads were evaluated from weeks 2 to 35 after challenge and the results are presented in Figure 3. The control of viral replication in animals immunized with SIV + IL$2+$ IL-15 DNA/rMVA-SIV indicated that this vaccine can provide a level of protection similar to that obtained after SIV DNA/Ad5 IM prime/boost vaccination. ${ }^{7,11,12,26}$ The viremia control observed with the DNA/rMVA in the IM group was comparable with DNA/Ad5, regardless of whether the analysis was carried out in Mamu- $\mathrm{A}^{\star} 01$-negative animals (middle panel) or in Mamu- $\mathrm{A}^{\star} 01$-positive animals (right panel). As previously observed, ${ }^{7,11,12,26}$ Mamu- $A^{\star} 01$-positive animals vaccinated IM (left panel, red dashed lines, and right panel, red line) showed a substantially better control of the viremia than Mamu- $A^{\star} 01$ negative animals (red lines, left and middle panels). When the DNA/rMVA vaccine was administered nasally, the difference in RNA viral loads between Mamu- $\mathrm{A}^{\star} 01$-positive animals (blue, dashed lines) and Mamu- $A^{\star} 01$-negative animals (blue lines) was not quite striking (left panel). However, the Mamu- $A^{\star} 01$ negative animals of the $\mathrm{N}$ group showed a better control of viral replication than those in the IM or the control group (middle panel, blue line). When RNA viral loads were compared during the chronic phase of the infection (weeks 8-36), statistically significant differences were observed between vaccinated Mamu- $\mathrm{A}^{\star} 01$-negative animals in the $\mathrm{N}$ or IM group and those in the control group ( $\mathrm{N}$ vs. control group $P=0.0002$; IM vs. control group $P<0.002$, second panel). At week 20 , the viral loads observed in Mamu- $\mathrm{A}^{\star} 01$-negative animals in the $\mathrm{N}$ group were significantly lower than those in the IM group $(P=0.008)$. On week 35 , the difference was not statistically significant, although there was a substantial difference in the averages for the animals in the two groups $(170,285$ copies per $\mathrm{ml}$ for the $\mathrm{N}$ group and 857,500 copies/ml for the IM group). At this time, two animals in the IM group and one in the $\mathrm{N}$ group had been killed because of AIDS, reducing the size of the groups and limiting the statistical power of the analysis. These results suggest that $\mathrm{N}$ vaccination in Mamu- ${ }^{*} 01$-negative animals may provide a better control of viral replication than the IM immunization. The IM vaccination provided a slightly better viremia control than the $\mathrm{N}$ vaccination in the Mamu- $\mathrm{A}^{\star} 01$-positive animals but there was no significance between the difference of the viral loads of $\mathrm{N}$ and IM groups, probably because there are only two animals per group and there was substantial variation between the two values at any given time point. Significantly lower viremia was detected in both vaccinated groups compared with the control group $(P=0.008)$.

\section{Post-challenge evaluation of CD4 ${ }^{+} \mathrm{T}$-cell populations and AIDS progression}

$\mathrm{CD} 4^{+}$and $\mathrm{CD} 8{ }^{+} \mathrm{T}$ cells were evaluated as the percentage of total $\mathrm{CD}^{+} \mathrm{T}$ cells in blood and as number per microliter $(\mu \mathrm{l})$ during the post-challenge time course. The percentage and absolute counts of $\mathrm{CD} 4^{+} \mathrm{T}$ cells in each animal are reported in Figure $\mathbf{3 b}$ and $\mathbf{c}$. When the analysis was carried out on Mamu$\mathrm{A}^{\star} 01$-negative animals (middle panels), no significant difference was detected in the $\mathrm{CD} 4^{+} \mathrm{T}$-cell population among groups during the early phase of the infection, confirming the previously observed fact that the $\mathrm{CD} 4^{+} \mathrm{T}$-cell count is not a parameter that permits early prediction of outcome. However, significant differences became evident between groups after week 28 (CD4 ${ }^{+}$T-cell percent value: $P=0.002$ ( $\mathrm{N}$ vs. control), $P=0.03$ (IM vs. control), and $P=0.02$ ( $\mathrm{N}$ vs. IM); $\mathrm{CD} 4^{+} \mathrm{T}$-cell absolute value: $P=0.03$ ( $\mathrm{N}$ vs. control), $P=0.03$ (IM vs. control), and $P=0.03$ ( $\mathrm{N}$ vs. IM)). When only Mamu- ${ }^{\star} 01$-positive animals were considered (right panels), significant differences of $\mathrm{CD} 4^{+}$ 

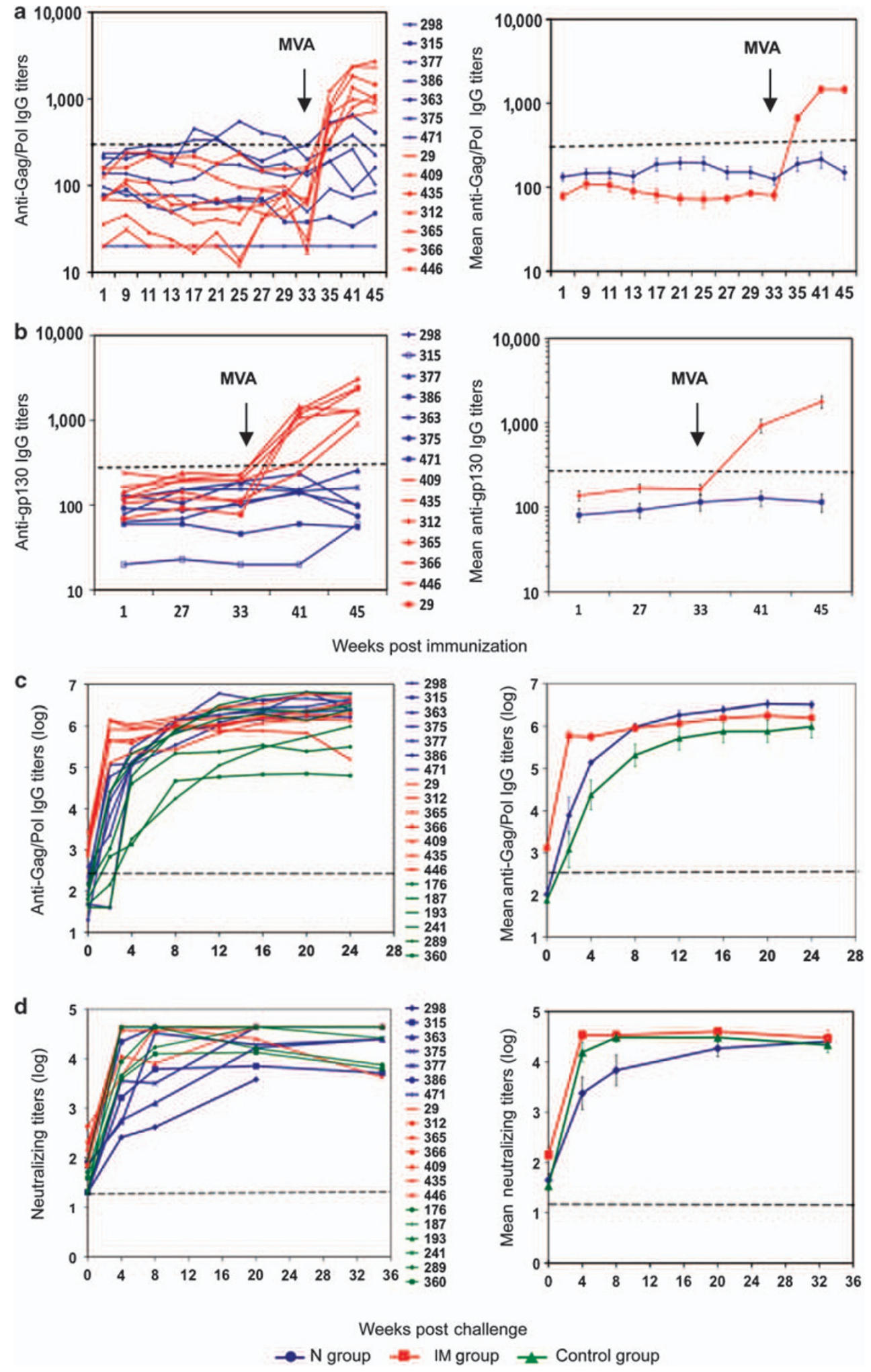

Figure 1 Plasma anti-SIV IgG titers (left panels) and geometric means (right panels) during vaccination and post challenge. Reciprocal end point titers of plasma (a) anti-SIV GaglPol IgG titers and (b) anti-SIV gp130 were measured during immunization and on the day of the challenge (week 45). The titers for each macaque are shown in the left panel, the geometric mean for each group is shown in the right panel. A postimmunization plasma sample was considered to have a significant titer of antibody if it was 3.4-fold greater than that in the corresponding pre-immune plasma. The $\mathrm{N}$ immunization group is represented in blue and the IM group is in red. The arrows indicate the rMVA boost at week 33 weeks after immunization. Reciprocal end point titers of (c) anti-SIV Gag/Pol titers and (d) anti-Env neutralizing antibodies are reported for plasma samples collected on the day of the challenge (week 0 ) and post challenge at 4 week intervals up to week 36 . Error bars represent standard error of the mean (s.e.m). IM, intramuscular; N, nasal; rMVA, recombinant modified vaccinia virus Ankara; SIV, Simian immunodeficiency virus. 

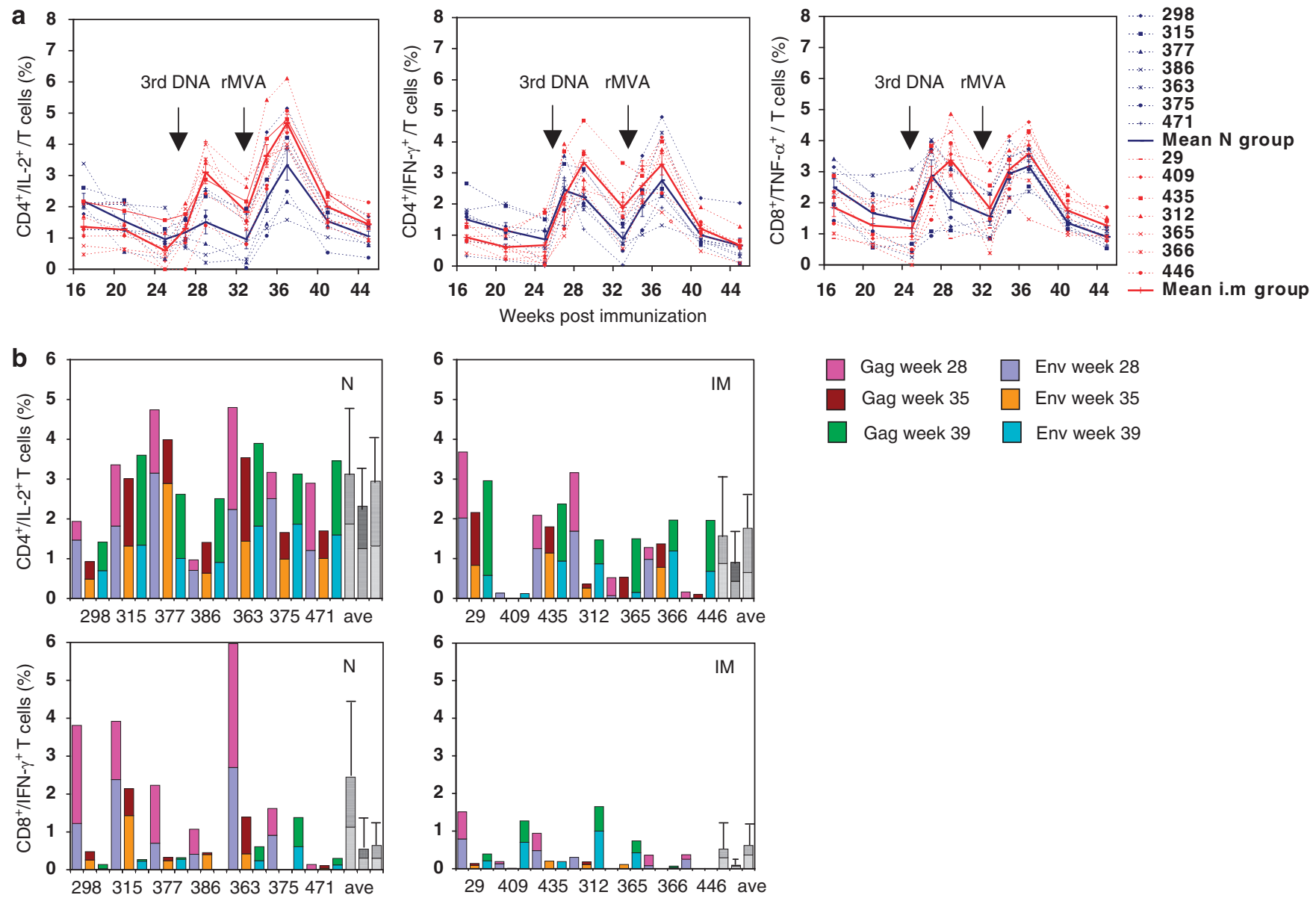

Figure 2 SIV-specific cell-mediated immune responses. Percentage of SIV-specific T cells detected in PBMCs (a) and in rectal biopsies (b) by intracellular staining after stimulation with SIV Gag or Env peptide pool. (a) Values for each individual animal (dotted line) and the group mean (filled line) are reported as the sum of percentage of Gag-specific and Env-specific cells detected during vaccination starting on week 16 and up to the day of challenge (week 45). (b) Percentage of SIV-specific T-cell responses measured in lymphocytes isolated from rectal biopsies on weeks 28, 35, and 39 after vaccination is shown for each animal. $\mathrm{N}$ marks panels showing results for $\mathrm{N}$ immunized animals and IM marks panels showing results for the intramuscularly vaccinated animals. Gray bars indicate the group mean and s.e.m. IM, intramuscular; N, nasal; PBMC, peripheral blood mononuclear cell; SIV, Simian immunodeficiency virus.

T-cell percentage values were observed early in the infection between the groups (weeks 8-44; $\mathrm{N}$ vs. control: $P=0.0001 ; \mathrm{N}$ vs. IM: $P=0.006$; and IM vs. control: $P=0.002$ ). In these animals, no significant differences were observed for the $\mathrm{CD} 4{ }^{+} \mathrm{T}$-cell absolute values. Time points collected after week 44 were not plotted, as the number of animals became progressively smaller because of killing.

As reported by others, ${ }^{26,34}$ preservation of the $\mathrm{CD} 4{ }^{+} \mathrm{C}_{\mathrm{M}}$ $\mathrm{T}$-cell population early after the infection is a better predictor of disease delay than total $\mathrm{CD} 4^{+} \mathrm{T}$-cell counts. Over the postchallenge time course, the $\mathrm{CD}^{+} \mathrm{C}_{\mathrm{M}}$ T-cell population was significantly higher in vaccinated animals than that in the control group. Higher levels of $\mathrm{CD}^{+}$total memory, $\mathrm{C}_{\mathrm{M}}$, and effector memory $\left(\mathrm{E}_{\mathrm{M}}\right) \mathrm{T}$ cells during the early chronic phase of the infection (weeks 8 and 16) were observed in vaccinated animals compared with control group, whether the absolute counts or the percentage was used in the comparison (Figure 4a). When individual groups were compared with one another, significance was found for the $\mathrm{N}$ group compared with control group in the case of absolute counts and percentage of $\mathrm{CD}^{+}{ }^{+}$total memory,
$\mathrm{C}_{\mathrm{M}}$, and $\mathrm{E}_{\mathrm{M}} \mathrm{T}$ cells (Figure $\mathbf{4 b}$ ). When values measured in the IM group were compared with those of the control group, significance was found for the percentage of $\mathrm{CD}^{+}$total memory and for the absolute counts and percentage of $\mathrm{CD} 4^{+} \mathrm{E}_{\mathrm{M}} \mathrm{T}$ cells (Figure $4 \mathbf{b}$ ). When the same analysis was restricted to only the Mamu- $\mathrm{A}^{\star} 01$-negative animals, significance was found for absolute counts and the percentage of $\mathrm{CD}^{+}$total memory and $\mathrm{C}_{\mathrm{M}}$ $\mathrm{T}$ cells when the $\mathrm{N}$ group was compared with the control group (Figure 4c); for the percentage of $\mathrm{CD} 4^{+}$total memory and for absolute counts and the percentage of $\mathrm{CD}^{+}{ }^{+} \mathrm{C}_{\mathrm{M}} \mathrm{T}$ cells when the $\mathrm{N}$ group was compared with the IM group; and for the percentage of the $\mathrm{CD} 4^{+} \mathrm{E}_{\mathrm{M}} \mathrm{T}$ cells when IM group was compared with the control group (Figure 4c). The $\mathrm{CD} 4^{+}$percentage of $\mathrm{CD} 4{ }^{+} \mathrm{C}_{\mathrm{M}}$ T cells in colorectal biopsies obtained at week 29 post challenge was also significantly higher for the $\mathrm{N}$ group compared with that in the IM or control group (Figure 4d). Unfortunately, no earlier mucosal samples were available for this evaluation.

The levels of $\mathrm{CD}^{+} / \alpha 4 \beta 7^{+} \mathrm{T}$ cells in blood have been described to accurately reflect their level in the gastrointestinal (GI) tract. ${ }^{35}$ When we analyzed the percentage and number 
a
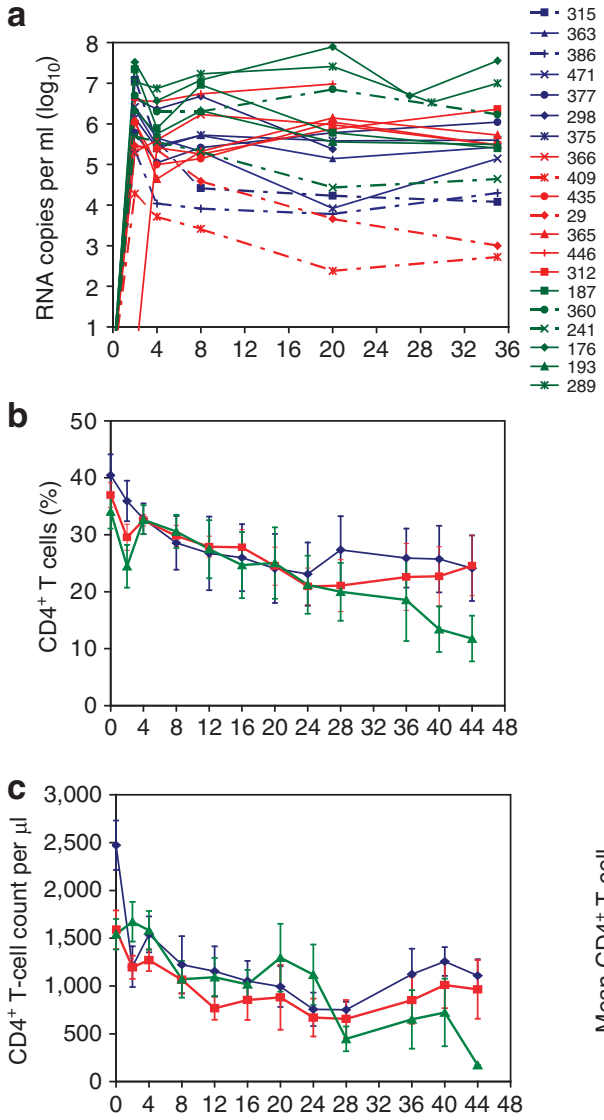
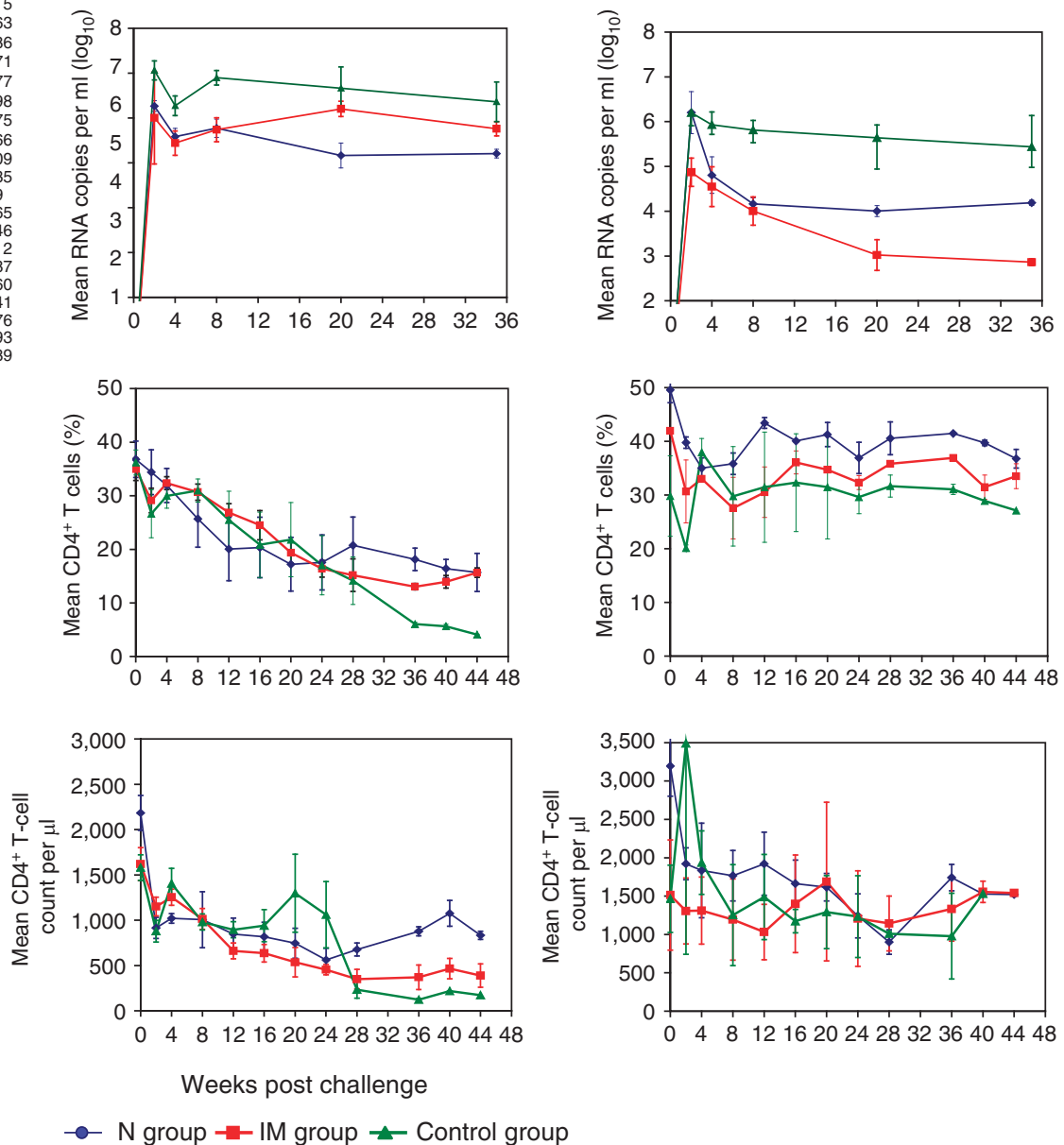

Figure 3 Plasma SIV RNA viral loads and peripheral CD4+ T-cell counts after infection. (a) Plasma SIV RNA viral loads are expressed as log ${ }_{10}$, after infection. RNA copies per $\mathrm{ml}$ of plasma are reported for each animal (first panel). Geometric means for each group are reported for MamuA*01negative (second panel) and MamuA*01-positive (third panel) macaques. Mean values of $\mathrm{CD}^{+}{ }^{+} \mathrm{T}$-cell counts are reported as percentage (b), or as counts per $\mu \mathrm{l}$ (c) for each group (first panel); average values are also reported for each vaccination group for MamuA*01-negative macaques (second panel) and for MamuA*01-positive macaques (third panel). Error bars indicate s.e.m. SIV, Simian immunodeficiency virus.

of $\mathrm{CD} 4^{+} / \alpha 4 \beta 7^{+} \mathrm{E}_{\mathrm{M}} \mathrm{T}$ cells in blood, we found that these cells were better preserved in $\mathrm{N}$ than in IM vaccinated animals or controls (Figure 4e). There was a significant inverse correlation between $\mathrm{CD}^{+} / \alpha 4 \beta 7^{+} \mathrm{E}_{\mathrm{M}} \mathrm{T}$-cell counts at week 16 postchallenge and viremia levels at week 53 post-challenge (Figure 4e, third panel).

Differences in long-term survival between groups were evaluated between different vaccination and control groups (Figure 5; all animals (a) and MamuA*01-negative only (b)), and by dividing the animals into two groups based on the 10 higher and 10 lower $\mathrm{CD}^{+} \mathrm{C}_{\mathrm{M}}$ T-cell counts on week 16 post-challenge (Figure 5c), or MamuA ${ }^{\star} 01$ - negative only (Figures 5d and $\mathbf{7}$ in each group). SIV vaccination delayed disease progression and a longer survival was observed in the vaccinated animals than in the controls. Median survivals for control, IM, and N groups were 36, 60, and $>96$ weeks (Figure 5a), and 28, 52, and $>96$ weeks for the MamuA*01-negative animals in these respective groups (Figure 5b). When survival in the $\mathrm{N}$ group was compared with that in the IM or control group, a statistical significance was observed whether the MamuA ${ }^{*} 01$-positive animals were included (Figure 5a, $P=0.03$ and $P=0.05$, respectively, by log-rank test) or excluded (Figure 5b, $P=0.05, P=0.03$ ). For the $\mathrm{N}$ group, an end point survival of 96 weeks (the time of closure of the experiment) was assigned even if more than $50 \%$ of the animals were still alive at that point. There was also statistical significance when the survival of animals with values in the top half of $\mathrm{CD} 4{ }^{+} \mathrm{C}_{\mathrm{M}}$ T-cell counts on week 16 post-challenge was compared with that of the animals with values in the bottom half of $\mathrm{CD}^{+}{ }^{+} \mathrm{C}_{\mathrm{M}} \mathrm{T}$ cells (Figure $5 \mathrm{c}$ : all animals $P=0.03$; Figure $5 \mathrm{~d}$ : MamuA ${ }^{\star} 01$-negative only, $P=0.03$ ).

In summary, these data confirm the finding that the preservation of $\mathrm{CD}^{+} \mathrm{C}_{\mathrm{M}}$ T-cell counts at an early stage of the chronic infection is associated with better survival, regardless of the vaccination regimen. They also indicate that the $\mathrm{N}$ vaccination resulted in a more significant preservation of the $\mathrm{CD} 4^{+} \mathrm{T}$-cell population in the GI tract at early time points after challenge and longer disease protection than the IM vaccination.

\section{Immunological correlates of post-challenge protection}

Post-challenge antiviral IgG levels, neutralizing antibodies, and T-cell immune responses were not substantially different over time between the groups (Figures $\mathbf{1 c}$ and $\mathbf{d}$ and $\mathbf{6 a}$ ). However, 

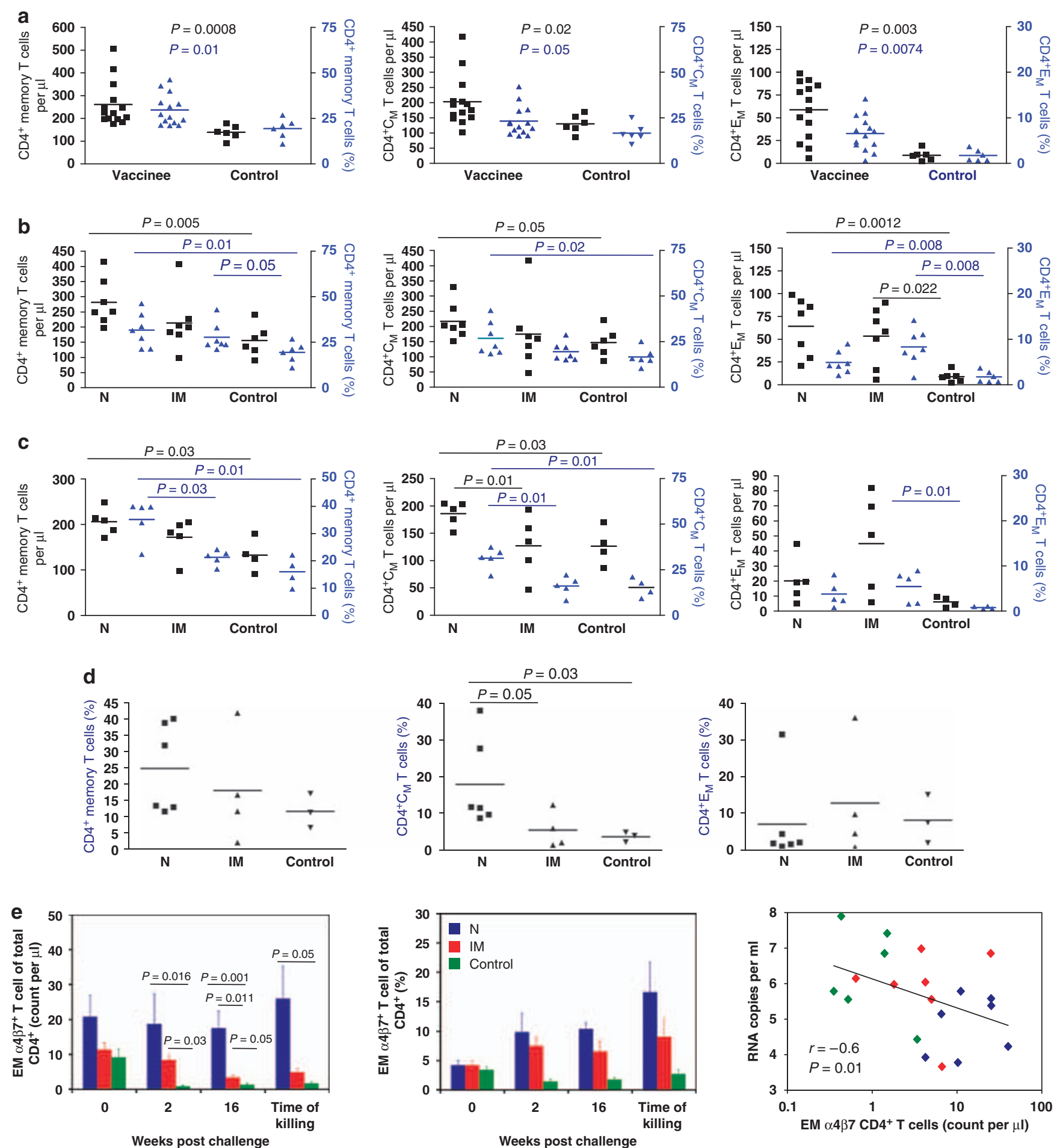

Figure $4 \mathrm{CD} 4^{+}$total memory, $\mathrm{C}_{\mathrm{M}}, \mathrm{E}_{\mathrm{M}}$, and $\mathrm{CD} 4^{+} / \alpha 4 \beta 7^{+} \mathrm{T}$-cell populations after challenge. Absolute $\mathrm{CD} 4^{+} \mathrm{T}$-cell count of total, $\mathrm{C}_{\mathrm{M}}\left(\mathrm{CD} 95^{+} / \mathrm{CD} 28^{+}\right)$, and $\mathrm{E}_{\mathrm{M}}\left(\mathrm{CD} 5^{+} / \mathrm{CD}^{-} 8^{-}\right) \mathrm{T}$ cells in PBMCs of (a) vaccinated and control animals and (b) in individual groups. (c) MamuA*01-positive animals were excluded from the analysis. The values measured at weeks 8 and 16 after challenge are averaged and are reported for each animal. (d) Percentage of $\mathrm{CD}^{+}$total memory, $\mathrm{C}_{\mathrm{M}}$, and $\mathrm{E}_{\mathrm{M}}$ T cells isolated from rectal biopsies for each animal in the vaccinated and control groups, measured 29 weeks post challenge. (e). Average CD4+/ $\alpha 4 \beta 7 \mathrm{E}_{\mathrm{M}}$ T-cell counts per $\mu$ in PBMCs of the three animal groups (left panel); average percentage of CD4+/ $\alpha 4 \beta 7^{+} \mathrm{E}_{\mathrm{M}}$ T cells of total CD4 ${ }^{+} / \alpha 4 \beta 7^{+} \mathrm{T}$ cells in PBMCs of the three animal groups (middle panel); correlation analysis between $\mathrm{CD} 4^{+} / \alpha 4 \beta 7^{+} \mathrm{E}_{\mathrm{M}} \mathrm{T}^{\mathrm{T}}$-cell counts per $\mu$ in PBMCs at week 16 and viral loads per $\mathrm{ml}$ at week 53 post challenge (right panel). The color of the symbol used for each animal in the right panel indicates the group to which the animal belongs. Bars indicate s.e.m. The $P$-values reported for each pair comparison were calculated using the Mann-Whitney test. $\mathrm{C}_{\mathrm{M}}$, central memory; $\mathrm{E}_{\mathrm{M}}$, effector memory; PBMC, peripheral blood mononuclear cell. 

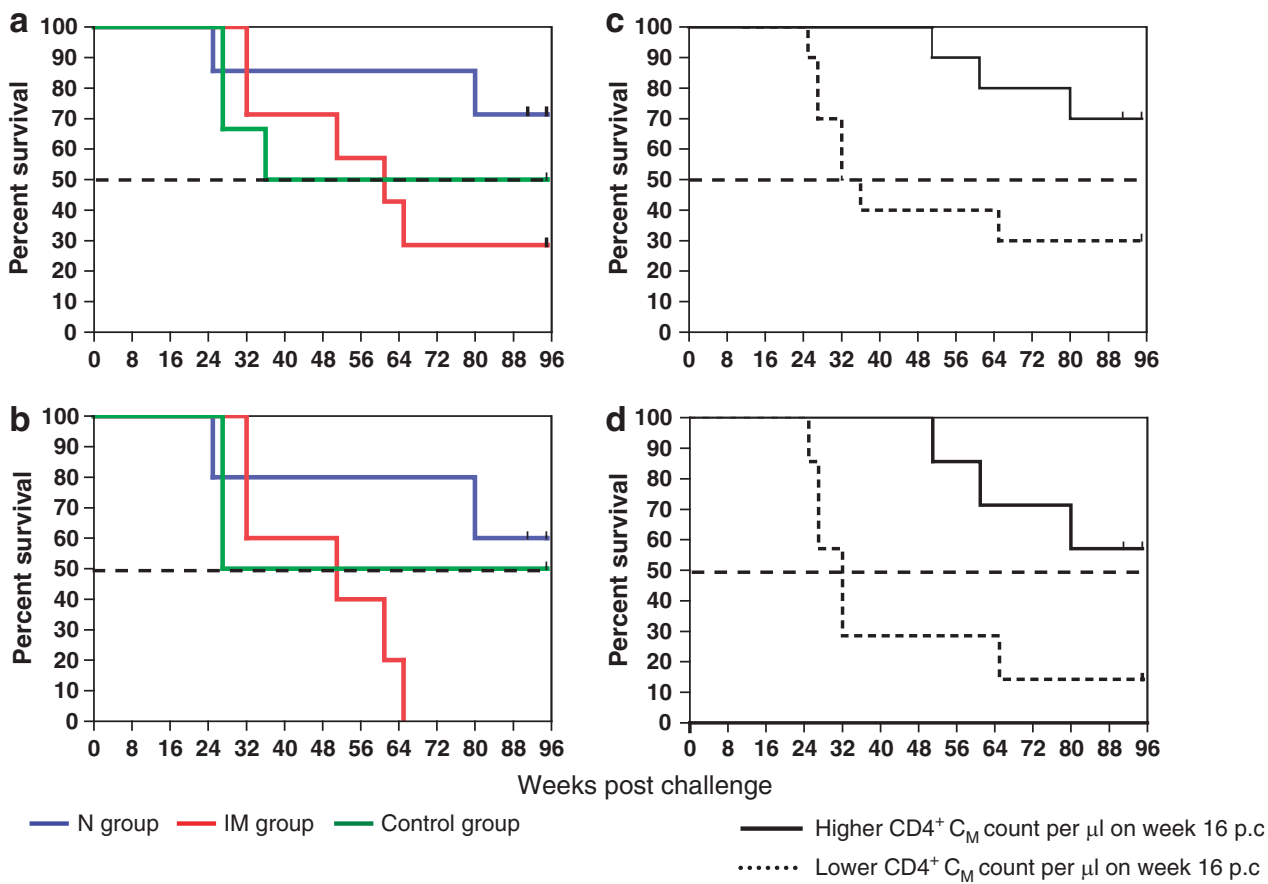

Figure 5 Kaplan-Meier survival curves after challenge. (a) Survival curves shown for the individual groups (N, IM, and control). (b) MamuA*01-positive macaques are excluded. (c) Survival curves for all animals divided in two 10 -animal groups based on $\mathrm{CD}^{+} / \mathrm{C}_{\mathrm{M}} \mathrm{T}_{\text {-cell }}$ count at week 16 post challenge (group assignment is reported in Table 2 legend). (d) MamuA*01-positive macaques are excluded. $\mathrm{C}_{\mathrm{M}}$, central memory; IM, intramuscular; $\mathrm{N}$, nasal; p.c., post challenge.

anti-Gag/Pol IgG titers in the IM group were significantly greater than those in the $\mathrm{N}$ group on the day of challenge, weeks 2 and 4 post challenge ( $P=0.0017, P=0.0027$, and $P=0.0350$, respectively). They did not differ significantly starting on week 8 post challenge and thereafter. The anti-Gag/Pol IgG titers in the IM group were significantly higher than those in the naive control group on the day of challenge, weeks 2,4 , and 8 after challenge $(P=0.0027, P=0.0039, P=0.0223$, and $P=0.0101$, respectively). The only time point at which anti-Gag/Pol IgG titers in the N group were significantly greater than those in the control group was at week 8 post challenge $(P=0.0374)$. These data suggest an anamnestic response in the IM group but not in the $\mathrm{N}$ group. No statistically significant differences between groups were detected at week 12 and at later time points.

Low neutralizing antibody titers against a highly neutralization-sensitive T cell line adapted stock of SIVmac251 were detected on the day of challenge in most vaccinated animals, with highest titers in the IM group. The titers increased rapidly by 4 weeks post challenge in all animals, but were significantly lower in the $\mathrm{N}$ group compared with the IM and control groups $(P=0.02$ and $P=0.05$, respectively). No statistical significance was found when values were compared between groups on week 8 and at later time points. On the day of challenge, antibodies were not able to neutralize SIVmac239, a virus that more closely resembles the neutralization-resistant phenotype of the challenge virus. After challenge, neutralizing antibodies against SIVmac239 were low or absent (data not shown).

When anti-SIV IgA antibodies were measured in rectal secretions post challenge (Table 2), five of six animals that developed AIDS during the 64 weeks of this analysis were found to have no or only transient anti-SIV IgA responses. Surviving animals in the $\mathrm{N}$ and IM groups had no significant differences in the magnitude or frequency of SIV-specific IgA responses. However, when the animals were stratified on the basis of high vs. low $\mathrm{CD} 4^{+} / \mathrm{C}_{\mathrm{M}}$ T cells (Table 2, legend), the group with better $\mathrm{CD} 4{ }^{+} / \mathrm{C}_{\mathrm{M}}$ preservation was observed to have significantly greater frequencies of SIV Gag-Pol-specific rectal IgA responses throughout the post-challenge time course $(P=0.04)$. The animals with the best early preservation of $\mathrm{CD} 4^{+} / \mathrm{C}_{\mathrm{M}}$ and $\mathrm{CD} 4^{+} / \alpha 4 \beta 7+\mathrm{E}_{\mathrm{M}} \mathrm{T}$ cells (Table 2, legend) also showed SIV Gag-Pol-specific rectal IgA at significantly more consecutive post-challenge time points than those that lost these cells $(P=0.03$ and $P=0.04)$. These data indicate that preservation of $\mathrm{CD} 4^{+} / \mathrm{C}_{\mathrm{M}}$ and $\mathrm{CD} 4^{+} / \alpha 4 \beta 7^{+} \mathrm{E}_{\mathrm{M}} \mathrm{T}$ cells is critical to the development and maintenance of GI IgA B-cell responses.

In the case of cell-mediated immunity, significant differences were not observed between groups (Figure 6a). However, when the animals were divided in two groups based on the 10 highest and the 10 lowest $\mathrm{CD} 4{ }^{+} \mathrm{C}_{\mathrm{M}} \mathrm{T}$-cell counts at week 53 post challenge, a parameter chosen as an indication of long-term preservation of the immune system, macaques with a higher level of $\mathrm{CD} 4{ }^{+} \mathrm{C}_{\mathrm{M}} \mathrm{T}$-cell counts at this time point had significantly higher $\mathrm{CD}^{+} / \mathrm{TNF}-\alpha^{+}(P=0.015)$ and $\mathrm{CD} 8^{+} / \mathrm{IFN}-\gamma^{+}(P=0.046)$ T-cell responses in the peripheral blood mononuclear cells (PBMCs) (Figure 6b). Furthermore, when the animals were divided in two groups based on the viral load level observed at week 53 post challenge ( 10 animals with values below and 10 with values above $5 \times 10^{4}$ copies per $\mathrm{ml}$ ) and SIV-specific cellular immune responses were compared, the animals with the better long-term viremia control had statistically higher levels of $\mathrm{CD} 4^{+} / \mathrm{IFN}-\gamma^{+}(P=0.02)$, 

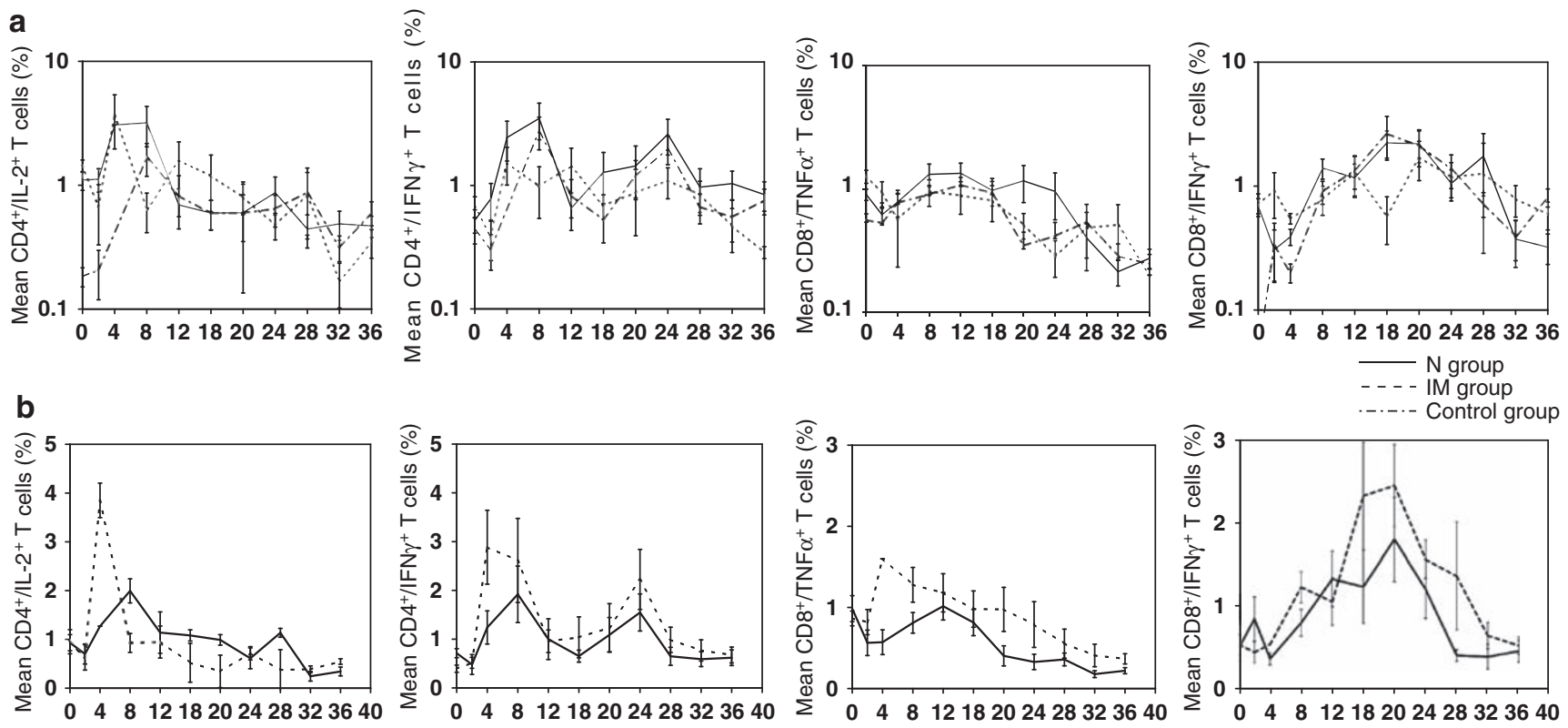

- - - High CD4+ $\mathrm{C}_{\mathrm{M}}$ count per $\mu \mathrm{l}$ (week 53)
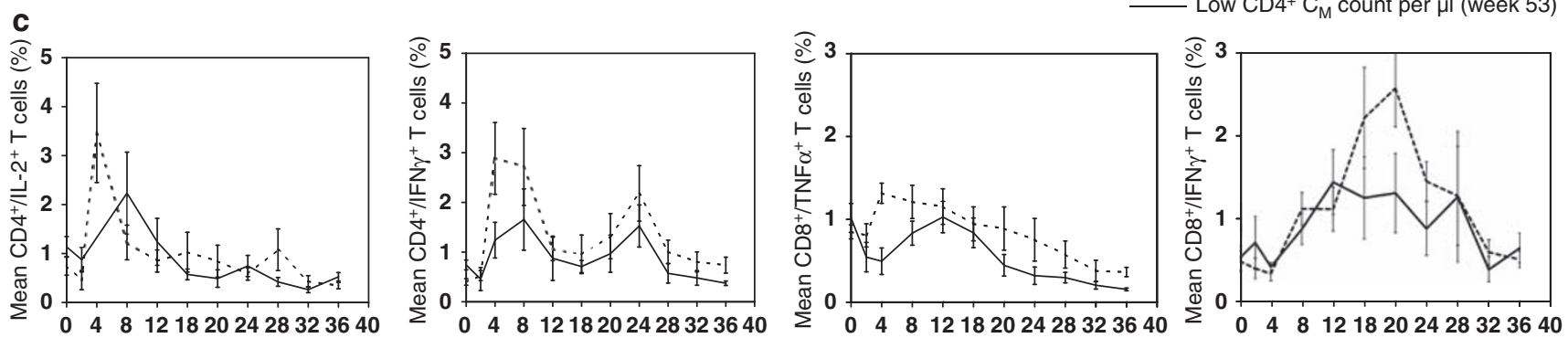

Weeks post challenge

- - - VL $<5 \times 10^{4}$ SIV RNA copies per $\mu$ l (week 53)

d

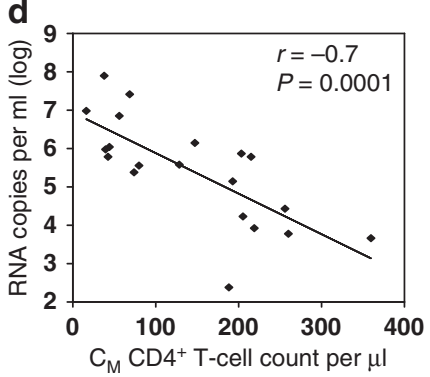

Figure 6 Circulating SIV-specific cell-mediated responses after challenge. (a) Group (N, IM, and control) averages and s.e.m. of the sum of percentage of Gag-specific and Env-specific cells detected after challenge in each group are reported. Average and s.e.m. of SIV-specific cell-mediated responses observed after grouping the animals in two 10-animal groups according the CD4+ $\mathrm{C}_{\mathrm{M}} \mathrm{T}$-cell counts (b) or viral loads (c) at week 53. (d) Correlation analysis between $\mathrm{CD}^{+} \mathrm{C}_{\mathrm{M}}$ T-cell counts and viral loads at week 53 post challenge. $\mathrm{C}_{\mathrm{M}}$, central memory; IM, intramuscular; N, nasal; p.c., post challenge; SIV, Simian immunodeficiency virus.

$\mathrm{CD}^{+} / \mathrm{IFN}-\gamma^{+}(P=0.05)$, and $\mathrm{CD} 8^{+} / \mathrm{TNF}-\alpha^{+}(P=0.05) \mathrm{T}$ cells during the entire post-challenge time course (weeks 0-36 post challenge) (Figure 6c). Interestingly, a very similar group composition was observed when the two above criteria were used to group the animals. Of the 10 animals, 8 with higher $C_{M}$ values were also present in the lower viral load group, supporting a correlation between $\mathrm{CD} 4{ }^{+} \mathrm{C}_{\mathrm{M}}$ T-cell long-term preservation and long-term viremia control. Indeed, a correlation analysis between $\mathrm{CD} 4{ }^{+} \mathrm{C}_{\mathrm{M}} \mathrm{T}$ cell counts and viral loads at week 53 post challenge showed a significant inverse correlation $(r=-0.7$, $P=0.0001$, Figure 6d). No significant difference between the levels of PBMC CD4 ${ }^{+}$and $\mathrm{CD} 8^{+}$T-cell responses was observed between the $\mathrm{N}$ and the IM group pre-challenge, indicating that the $\mathrm{N}$ and IM immunizations were equally capable of stimulating these responses systemically. These data indicate that these systemic immune responses contribute to the preservation of $\mathrm{CD}^{+} \mathrm{C}_{\mathrm{M}} \mathrm{T}$ cells and control of viremia regardless of the route of immunization by which they were achieved. 

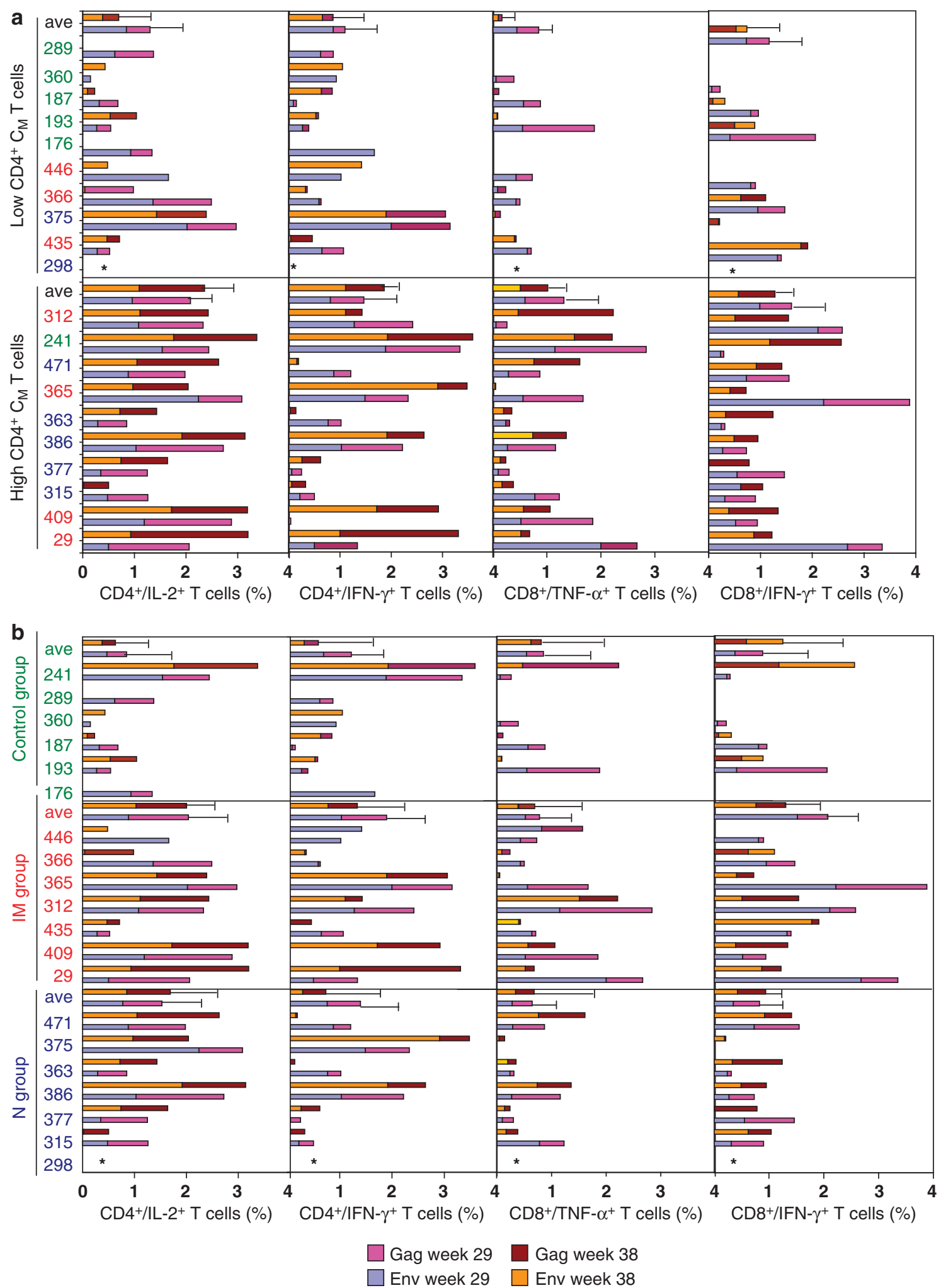

Figure 7 SIV-specific cell-mediated responses in the gastrointestinal lymphoid associated tissue at two time points after challenge. Percentage of SIV-specific $\mathrm{CD}^{+}{ }^{+}$or $\mathrm{CD}^{+} / \mathrm{CD}^{+} \mathrm{T}$ cells producing IL-2, IFN- $\gamma^{+}$, and TNF- $\alpha^{+}$in lymphocytes isolated from rectal biopsies on weeks 29 and 38 post challenge, after stimulation with SIV Gag or SIV Env pools peptides. Animals were divided in two groups based on PBMC $C_{M}$ CD4 ${ }^{+}$T-cell counts 53 weeks post challenge (a) or according to the vaccination groups (b). Asterisk indicates that data are not available for that particular animal. $\mathrm{C}_{\mathrm{M}}$, central memory; IL, interleukin; IFN, interferon; PBMC, peripheral blood mononuclear cell; SIV, Simian immunodeficiency virus; TNF, tumor necrosis factor. 
Fold increase in ng anti-SIV gag/pol antibody per $\mu \mathrm{g}$ IgA

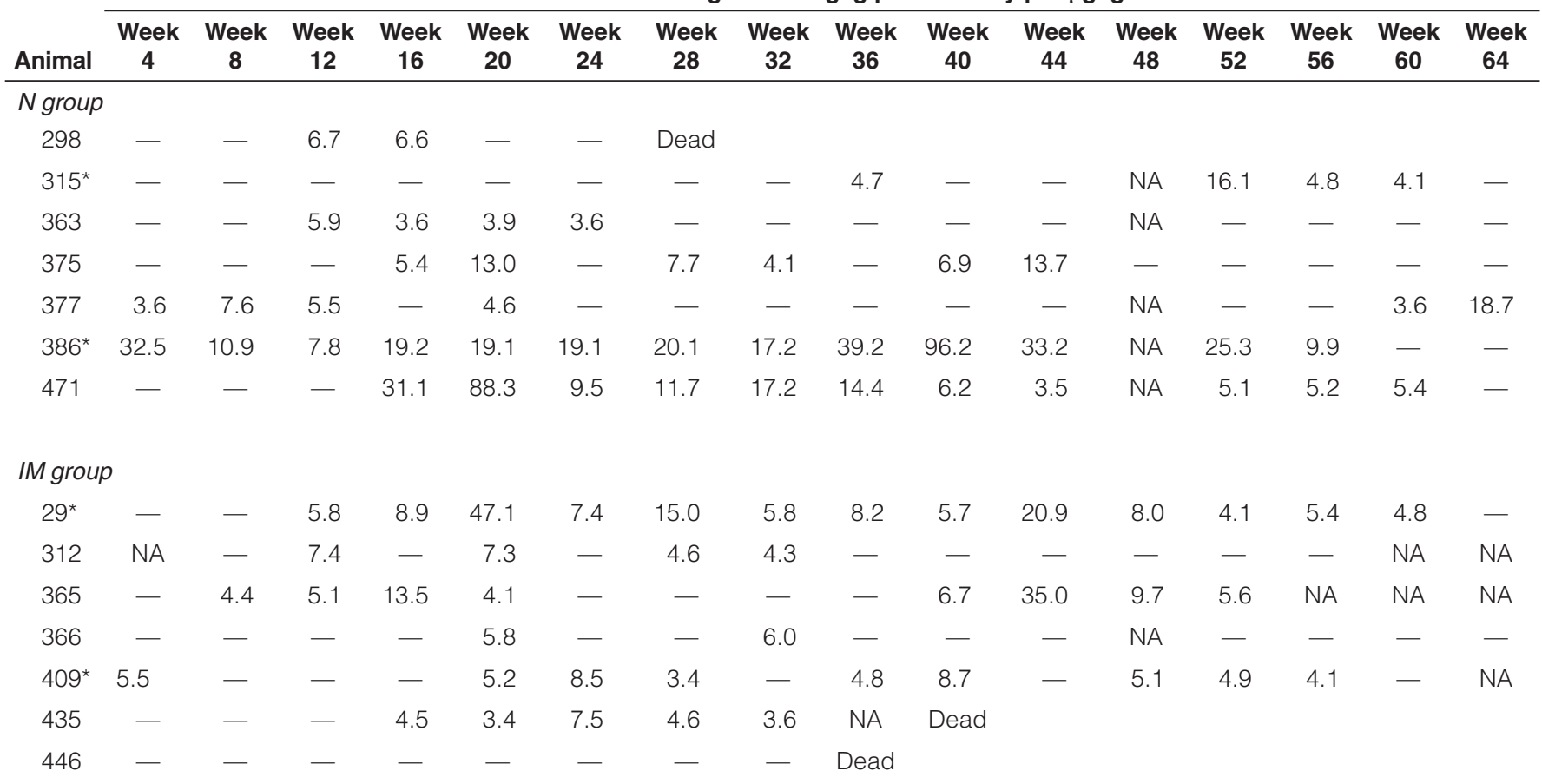

\section{Control group}

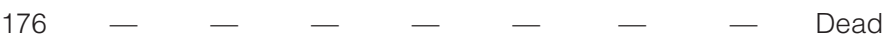

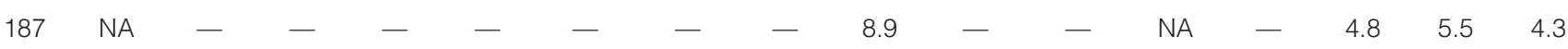

$$
\begin{aligned}
& \begin{array}{llllllllllllllll}
193 & 27.4 & 24.7 & 12.7 & 41.9 & 16.9 & 37.0 & 7.7 & 7.0 & 18.2 & 6.5 & 5.1 & 8.9 & - & 4.4 & 4.8
\end{array}
\end{aligned}
$$

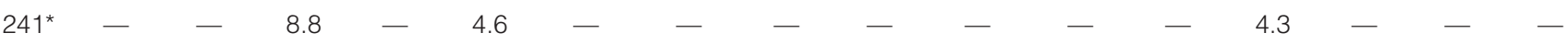

$$
\begin{aligned}
& 289-\quad-\quad-\quad-\quad-\quad-\quad-\quad-\quad \text { Dead }
\end{aligned}
$$

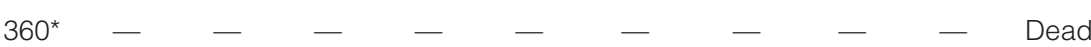

Fold increase in ng anti-SIV gp130 antibody per $\mu \mathrm{g} \lg \mathrm{A}$

\begin{tabular}{|c|c|c|c|c|c|c|c|c|c|c|c|c|c|c|c|c|}
\hline \multicolumn{17}{|c|}{$N$ group } \\
\hline 298 & - & - & 4.0 & 4.0 & - & - & Dead & & & & & & & & & \\
\hline $315^{\star}$ & - & 5.8 & 3.6 & 11.8 & 10.4 & 24.0 & 7.6 & 12.8 & 8.6 & - & - & NA & 23.4 & 6.6 & 5.5 & 8.5 \\
\hline 363 & - & - & - & 7.0 & 5.5 & - & - & - & - & - & - & NA & - & - & - & - \\
\hline 375 & - & - & - & - & - & - & - & - & - & - & - & - & - & - & - & - \\
\hline 377 & 4.0 & 4.2 & - & - & 4.1 & - & - & - & - & - & - & NA & 3.4 & - & - & 12.0 \\
\hline $386^{*}$ & - & - & - & - & 14.3 & - & - & - & - & - & - & NA & 5.0 & 3.9 & - & - \\
\hline 471 & - & - & - & 3.7 & 33.1 & 4.2 & 5.4 & 15.5 & 13.0 & - & - & NA & 4.1 & 5.0 & 3.8 & - \\
\hline
\end{tabular}

$\begin{array}{ccccccccccccccccc}\text { IM group } & & & & & & & & & & & \\ 29^{*} & 4.0 & 5.9 & 5.5 & 4.2 & 9.2 & 3.7 & 4.9 & 4.1 & 3.4 & - & 4.1 & 7.4 & 4.6 & 6.3 & 17.1 & 9.7 \\ 312 & \text { NA } & - & 9.9 & 3.6 & 17.3 & 13.1 & 5.8 & 5.2 & - & - & - & - & 8.7 & 4.5 & \text { NA } & \text { NA } \\ 365 & 9.1 & 6.7 & 4.6 & 33.3 & 9.7 & 5.5 & 3.6 & 3.8 & 4.9 & - & - & 6.7 & 4.9 & \text { NA } & \text { NA } & \text { NA } \\ 366 & - & 4.2 & 8.1 & - & 5.5 & 3.7 & - & 7.0 & - & - & - & \text { NA } & 16.6 & 9.0 & 5.9 & - \\ 409^{*} & 7.0 & 5.9 & 3.4 & - & - & - & 3.4 & - & - & - & - & 6.7 & 7.0 & 7.1 & 3.9 & \text { NA } \\ 435 & 5.6 & 3.6 & 4.3 & - & 3.8 & - & - & - & \text { NA } & \text { Dead } & & & & & \end{array}$


Table 2 Continued

\begin{tabular}{|c|c|c|c|c|c|c|c|c|c|c|c|c|c|c|c|c|}
\hline \multicolumn{17}{|c|}{ Control group } \\
\hline 176 & - & - & - & - & - & - & - & Dead & & & & & & & & \\
\hline 187 & NA & - & 21.4 & 37.0 & 67.1 & 142.5 & 214.3 & 224.2 & 135.5 & 231.8 & 490.5 & NA & 122.9 & 305.9 & 212.6 & 259.9 \\
\hline $241^{*}$ & - & - & 20.5 & 11.4 & 5.8 & 7.7 & 14.6 & 4.9 & - & 5.4 & 4.7 & 3.4 & - & - & - & NA \\
\hline 289 & - & - & - & - & - & - & - & Dead & & & & & & & & \\
\hline
\end{tabular}

For statistical analysis of these data, animals were also divided in two groups, based on CD4 +/CM counts at week 16 (higher: 29, 241, 315, 363, 193, 386, 409,

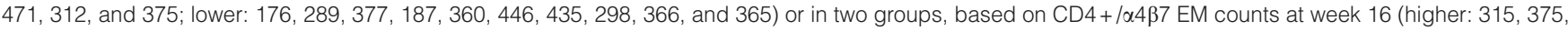
$298,409,377,386,29,363,312$, and 471; lower 435, 446, 241, 366, 289, 360, 365, 193, 176 and, 187). Animal numbers in the pair groups are listed according to the parameter ranking. NA: not available. *indicates MamuA*01-positive animals.

We analyzed SIV-specific immune responses in MNCs from colorectal biopsies (weeks 29 and 38 post challenge) (Figure 7). We found that animals with better long-term $\mathrm{CD} 4{ }^{+} \mathrm{C}_{\mathrm{M}} \mathrm{T}$-cell preservation at 53 weeks post challenge had significantly greater $\mathrm{SIV}$-specific $\mathrm{CD} 4^{+} / \mathrm{IL}-2^{+} \mathrm{T}$ cells in colorectal tissue than the animals with lower $\mathrm{CD} 4{ }^{+} \mathrm{C}_{\mathrm{M}}$ T cells (week 29: $P=0.01$; week 38: $P=0.03$; Figure 7a). No significance was detected for other responses $\left(\mathrm{CD}^{+} / \mathrm{IFN}-\gamma^{+}, \mathrm{CD} 8^{+} / \mathrm{IFN}-\gamma^{+}\right.$, and $\left.\mathrm{CD} 8^{+} / \mathrm{IFN}-\gamma^{+}\right)$ or when the same responses were compared between groups (Figure 7b). A more significant mucosal SIV-specific CD ${ }^{+} / \mathrm{IL}^{-}$ $2^{+} \mathrm{T}$-cell response could be detected in the $\mathrm{N}$ group before challenge (Figure 2b). Better stimulation of this response before challenge may explain why the $\mathrm{N}$ group had a better outcome than the IM vaccinated group.

The analysis of DNA viral loads in intestinal biopsies collected at the time of killing because of AIDS or closure of the experiment did not show significant difference (data not shown). It is unclear whether the significant $\mathrm{CD} 4{ }^{+} \mathrm{T}$-cell depletion present in the animals with AIDS is a reason for their low viral load in the GI tract and therefore lack of statistical significance when compared with healthy animals. Analysis of this parameter early in the post-challenge time course is not available.

These results indicate that the protection provided by our vaccine when given IM is similar to that provided to macaques by the DNA/rAd5 combination (median survival 1.9-fold higher for the $\mathrm{MamuA}^{*} 01$-negative IM group compared with the control in our study, $\sim 2$-fold in ref. ${ }^{26}$ ), which is considered at present one of the most effective vaccines available. ${ }^{12,26}$ Furthermore, these data also suggest that an $\mathrm{N}$ vaccination may actually provide better long-term protection from disease than the IM vaccination (median $\mathrm{N}$ group survival $>3.3$-fold than the control group).

\section{DISCUSSION}

Protection from AIDS appears an elusive goal with the current vaccination approaches. ${ }^{15,16} \mathrm{~A}$ reasonable conclusion from past and current approaches is that once a chronic infection is established, disease can be delayed if preexisting immunity is present but not avoided (Letvin et al, ${ }^{5}$ McMichael, ${ }^{6}$ Masopust, ${ }^{17}$ and references therein). If AIDS results from immunoactivation, and viral replication leads to immunoactivation, ${ }^{36,37}$ one could argue that if vaccination does not prevent the establishment of the systemic chronic infection, it could not prevent disease despite the fact that it may delay the onset of disease by limiting the rate of viral replication.
The experiments presented here indicate that a SIV + cytokines DNA/rMVA N vaccination provides a more significant protection from progression to AIDS than an IM vaccination. In clinical trials, testing of a $\mathrm{rAd} 5 / \mathrm{rAd} 5$ vaccine administered IM was unsuccessful. ${ }^{15,16}$ The use of rMVA as a boosting strategy may have a different outcome than the use of recombinant Ad5. As smallpox vaccination is no longer administered and the smallpox virus is eradicated, preexisting immunity to poxviruses should be absent in the majority of the human population. Therefore, the use of the DNA and MVA combination may actually be advantageous when compared with the use of an adenoviral vector in humans. MVA given nasally did not boost systemic antibody levels but, because of the compartmentalization of the immune system, it may have stimulated responses in the mucosa at the site of immunization, which was not sampled in our study. ${ }^{38}$ Alternatively, the infectivity in the nasal mucosa may be limited in primates, although MVA can quite efficiently infect the mouse mucosa. ${ }^{39}$ Lower viral loads in the GI tract, suggested by the preservation of the $\mathrm{CD}^{+} / \alpha 4 \beta 7^{+} \mathrm{T}$-cell population, and therefore lower amount of antigen to drive an antibody response, might explain the slower increase in post-challenge total neutralizing antibody titers in the $\mathrm{N}$ group.

Stimulation of humoral mucosal immunity was sporadic and not long lasting, whereas T-cell immunity was detected during the immunization protocol and at the time of challenge. Some of the significant responses detected in the animals with better outcome were also induced at higher levels in the same animals by the vaccine. Therefore, it seems reasonable to conclude that the better protection achieved by our SIV DNA/rMVA vaccination through the $\mathrm{N}$ route was because of the anti-SIV T-cell-mediated immunity stimulated by the vaccination in the GI tract. These findings are important because they provide evidence that mucosal vaccination may be a better approach than systemic vaccination toward the goal of protection from AIDS. These experiments support a thorough investigation of candidate vaccines administered through mucosal or combined mucosal-systemic routes.

Approaches aimed at optimizing the humoral mucosal immune response at the sites of HIV entry need to be considered and will be evaluated in future experiments. ${ }^{40}$ It is possible that in order to reach this goal, protein-based antigens or live vectors may be required as a component of a mucosal immunization. ${ }^{32,33,41}$ Establishing humoral antiviral immunity at the site of viral entry 
may provide the means to clear HIV infection before it becomes systemic or to significantly reduce its effect so that residual infectivity can be eliminated by cell-mediated immunity. ${ }^{42}$ To achieve this goal, there is a very limited window of opportunity, as data obtained from rhesus macaques indicated that the time from exposure to systemic infection is just a few days. ${ }^{43-45}$ However, it is also clear that low-dose exposures in female macaques are substantially less likely to result in systemic infection, ${ }^{43-45}$ suggesting that innate non-immunological clearance mechanisms combined with local antiviral immunity could increase the viral dose that can be controlled locally. Mucosal IgA could be particularly well suited to achieve this goal. To date, no vaccine approach has been able to achieve sustained high titer ant-SIV IgA in rectal secretions and in saliva (Letvin et al, ${ }^{5}$ McMichael, ${ }^{6}$ Masopust, ${ }^{17}$ and references therein). Our vaccination approach was also flawed by this limitation. However, the $\mathrm{N}$ vaccination provided a more prolonged survival than the IM vaccination. It is possible that the more significant anti-SIV T-cell mediated immunity stimulated in the GI tract by the $\mathrm{N}$ vaccination resulted in a better control of viral replication at this site, which, in turn, resulted in the observed better $\mathrm{CD} 4^{+} \mathrm{C}_{\mathrm{M}}$ and $\mathrm{CD} 4^{+} / \alpha 4 \beta 7^{+} \mathrm{T}$-cell preservation and disease protection. Unfortunately, evaluation of viral loads in GI tissues early on after SIV infection was not carried out.

This study highlights the importance of testing vaccine candidates through different mucosal routes as these routes of immunization could provide a different degree of protection than that observed after intramuscular (IM) vaccination. If the immunization through a particular mucosal route is better suited to provide a more substantial control of viral loads at the GI level, systemic viral loads could be reduced for longer periods of time with a more substantial impact on disease progression. Evaluating the outcome of the same immunization given through different systemic and mucosal routes could be valuable even for future vaccine approaches that differ from the one proposed here.

\section{METHODS}

Vaccine constructs. The DNA plasmid pVacc6 used in the vaccination is a derivative of $\mathrm{pVacc} 1 .{ }^{46} \mathrm{pVacc6}$ includes a full SIVmac239 genome with multiple mutations in the nucleocapsid basic domain and the functional domains of reverse transcriptase (RT), integrase (INT), and protease (PR) and a stop codon at the beginning of the $v p r$ gene. Gene expression is under the control of the CMV promoter, with deletions of both long terminal repeats. The profile of the non-infectious viral particles produced by the construct was evaluated as previously described. ${ }^{46}$ rMVA expressing SIV Gag-Pol and Env proteins was prepared as previously described. ${ }^{39}$ The interleukin (IL)-2/Ig and IL-15 plasmids were previously described. ${ }^{1,47}$ IL-2/Ig and IL-15 levels were tested in transfected 293T supernatant by ELISA (R\&D Systems, Minneapolis, MN).

Vaccine regimes and challenge. A total of 20 male rhesus macaques were divided into three groups: a $\mathrm{N}$ group ( $n=7, \mathrm{~N}$ immunized), an IM group ( $n=7$, IM immunized), and a control group ( $n=6$, naive animals). The DNA vaccine was suspended in saline solution at a concentration of $10 \mathrm{mg} / \mathrm{ml}$. Each N DNA immunization consisted of $2.5 \mathrm{mg}$ pVacc6, $0.5 \mathrm{mg}$ IL-2/Ig, and $0.5 \mathrm{mg}$ IL- 15 administered as a $350 \mu \mathrm{l}$ dose, $175 \mu \mathrm{l}$ in each nostril of the animal. Each IM DNA immunization consisted of $5 \mathrm{mg}$ pVacc6, $2.5 \mathrm{mg} \mathrm{IL-2/Ig}$, and $2.5 \mathrm{mg}$ IL-15 administrated as a $1 \mathrm{ml}$ dose. The three DNA doses were administered on day 1 of weeks 1, 9, and 25. rMVA ( $10^{9}$ p.f.u.), expressing SIV gag and pol and SIV env genes, was delivered N (N group) or IM (IM group) on week 33. Two animals per group were Mamu- $A^{\star} 01$-positive as determined by PCR. Starting from week 45 , vaccinated and control animals were inoculated rectally with a low dose $\left(0.2 \mathrm{AID}_{50}(50 \%\right.$ animal infectious dose $)$ in a rhesus macaque rectal titration corresponding to $\sim 100 \mathrm{TCID}_{50}(50 \%$ tissue culture infective dose)) of the pathogenic SIVmac251 virus, administered non-traumatically using a needle-less tuberculin syringe as cell-free virus in the rectum. Doses were repeated weekly until a reverse transcriptase-PCR assay on plasma-derived virus resulted positive.

Analysis of SIV-specific IgA in rectal secretions and IgG in plasma. Collection of rectal secretions and hemoglobin measurements in the eluted fluids were carried out as previously described. ${ }^{1,46,48}$ Hemoglobin averaged $0.07 \%$ of that in whole blood. SIV Gag/Pol or SIV Env-specific IgA antibodies in rectal secretions were quantitated as described. 1,2,4,46 For the ELISAs, microtiter plates were coated overnight with $100 \mathrm{ng}$ per well SIVmac251 rgp130 (ImmunoDiagnostics, Woburn, MA) or $100 \mu \mathrm{l}$ per well of 1:400 dilution of SIV viral lysate (Advanced Biotechnologies, Columbia, MD) that lacked detectable envelope protein at this dilution. Reactivity detected against the SIV lysate is therefore described as being against SIV Gag/Pol proteins. For SIV IgA and IgG assays, plasma from previously vaccinated macaques that developed gp130- or Gag/Pol-specific IgA or IgG after challenge was used as standards. All SIV standards were calibrated relative to the total IgA or IgG standard by coating portions of the same plate with SIV antigen, goat anti-monkey IgA, or goat anti-monkey IgG antibody (MP BioMedicals, Solon, OH). Bound IgG or IgA was detected with biotinylated affinity-purified goat anti-human IgG (SouthernBiotech, Birmingham, AL) or anti-monkey IgA antibody (Open Biosystems, Huntsville, AL), avidin-peroxidase, and tetramethylbenzidine (Sigma, St Louis, MO). To obtain titers of SIV Gag/Pol-specific IgG in plasma, the antibody concentrations (in $\mu \mathrm{g} \mathrm{ml}^{-1}$ ) were multiplied by 1,600 based on the finding from previous studies that this is the average reciprocal end point titer for $1 \mu \mathrm{g} \mathrm{ml}^{-1}$ specific IgG in this assay. ${ }^{1,2}$ Neutralization titers were measured as a function of Tat-induced luciferase reporter gene expression after single round of infection in either M7-Luc or TZM-bl cells. ${ }^{49}$ The viruses used in the neutralization assay were TCLA-SIVmac251 (M7-Luc assay) and SIVmac239CS (TZM-bl assay). Titers of SIV-specific neutralizing antibodies are the plasma dilution at which relative luminescence units were reduced to $50 \%$ compared with virus control wells after subtraction of background.

Isolation of intestinal MNCs and PBMCs. After Telazol anesthesia, 7-8 biopsies per animal per time point were obtained from the rectum using sterile forceps and a small pinch biopsy device (Olympus endoscopic biopsy forceps, Center Valley, PA). MNCs from colorectal biopsies were isolated according to previously published procedures. ${ }^{25} \mathrm{PBMC}$ were isolated by Ficoll (GE Healthcare Bio-science AB, Pittsburg, PA) density gradient centrifugation.

Intracellular staining and antibodies. MNCs $\left(10^{5}\right.$ cells $)$ and PBMCs $\left(10^{6}\right)$ were incubated for $14 \mathrm{~h}$ with medium alone (unstimulated) or $5 \mathrm{mg} \mathrm{ml}^{-1}$ pool of 15 -mer SIV Gag or SIV Env peptides. As positive control, cells were incubated with $10 \mathrm{ng} \mathrm{ml}^{-1}$ phorbol 12-myristate 13acetate (Sigma) and $1 \mu \mathrm{g} \mathrm{ml}^{-1}$ ionomycin (Sigma). All cultures contained Monensin (GolgiStop; BD Biosciences, San Jose, CA) and $1 \mu \mathrm{g} \mathrm{ml}^{-1}$ antiCD49d and anti-CD28 antibodies. The PBMCs and MNCs were stained and evaluated for the expression of cytokines according to previously described procedures. ${ }^{2}$ For MNCs, $200 \mu \mathrm{l}$ of a viability dye (VIVID, LIVE/DEAD kit, Invitrogen, Carlsbad, CA) was added to the antibody cocktail to exclude dead cells. Data for peptide-stimulated PBMCs are reported as percentage, determined after subtracting the percentage in non-stimulated cells. The antibodies used in this study were Mab11 (antiTNF- $\alpha$ ), B27 (anti-IFN- $\gamma$ ), MQ1-17H12 (anti-IL2), DX2 (anti-CD95), L200 (anti-CD4), SP34-2 (anti-CD3), and SK1 (anti-CD8).

Viral load quantitation. Plasma SIV RNA levels were measured by realtime reverse transcriptase-PCR assay, as described. ${ }^{50}$ The assay has a threshold sensitivity of 100 copy equivalents per milliliter. Interassay variation is $<25 \%$ (coefficient of variation). 
Statistical analysis. Calculations and statistical analyses were carried out using the GraphPad Prism, San Diego (version 3 software). End point antibody titers and RNA viral loads were logarithmically transformed, and the geometric means were calculated for each vaccination group. Within- or between-group comparisons were carried out by two-tailed, $t$-test, or Mann-Whitney test, respectively. The two-tailed Fisher exact test was used to compare the frequency of rectal IgA responses between groups. Correlation analysis was carried out using the Spearman rank test. Survival distributions were evaluated using the Kaplan-Meier method and the log-rank test was used to compare survival curves between groups. Results of statistical analyses were considered significant if they produced $P \leqslant 0.05$.

\section{ACKNOWLEDGMENTS}

The work was supported by an NIH-NIAID grant to A.A. (RQ1AI058707).

\section{DISCLOSURE}

The authors declared no conflict of interest.

2009 Society for Mucosal Immunology

\section{REFERENCES}

1. Bertley, F.M. et al. Control of simian/human immunodeficiency virus viremia and disease progression after IL-2-augmented DNA-modified vaccinia virus Ankara nasal vaccination in nonhuman primates. J. Immunol. 172, 3745-3757 (2004).

2. Manrique, M. et al. DNA-MVA vaccine protection after X4 SHIV challenge in macaques correlates with day-of-challenge antiviral CD4+ cellmediated immunity levels and postchallenge preservation of $\mathrm{CD} 4+\mathrm{T}$ cell memory. AIDS Res. Hum. Retroviruses 24, 505-519 (2008).

3. Sun, Y., Santra, S., Schmitz, J.E., Roederer, M. \& Letvin, N.L. Magnitude and quality of vaccine-elicited T-cell responses in the control of immunodeficiency virus replication in rhesus monkeys. J. Virol. 82, 8812-8819 (2008).

4. Wang, S.W. et al. An SHIV DNA/MVA rectal vaccination in macaques provides systemic and mucosal virus-specific responses and protection against AIDS. AIDS Res. Hum. Retroviruses 20, 846-859 (2004).

5. Letvin, N.L., Barouch, D.H. \& Montefiori, D.C. Prospects for vaccine protection against HIV-1 infection and AIDS. Annu. Rev. Immunol. 20, 73-99 (2002).

6. McMichael, A.J. HIV vaccines. Annu. Rev. Immunol. 24, 227-255 (2006).

7. Casimiro, D.R. et al. Attenuation of simian immunodeficiency virus SIVmac239 infection by prophylactic immunization with DNA and recombinant adenoviral vaccine vectors expressing Gag. J. Virol. 79, 15547-15555 (2005).

8. Egan, M.A. et al. Simian immunodeficiency virus (SIV) gag DNAvaccinated rhesus monkeys develop secondary cytotoxic T-lymphocyte responses and control viral replication after pathogenic SIV infection. J. Virol. 74, 7485-7495 (2000).

9. Lu, S. et al. Simian immunodeficiency virus DNA vaccine trial in macaques. J. Virol. 70, 3978-3991 (1996).

10. Hel, Z. et al. Containment of simian immunodeficiency virus infection in vaccinated macaques: correlation with the magnitude of virus-specific pre- and postchallenge CD4+ and CD8+ T cell responses. J. Immunol. 169, 4778-4787 (2002).

11. McDermott, A.B. et al. Cytotoxic T-lymphocyte escape does not always explain the transient control of simian immunodeficiency virus SIVmac239 viremia in adenovirus-boosted and DNA-primed Mamu-A*01-positive rhesus macaques. J. Virol. 79, 15556-15566 (2005).

12. Wilson, N.A. et al. Vaccine-induced cellular immune responses reduce plasma viral concentrations after repeated low-dose challenge with pathogenic simian immunodeficiency virus SIVmac239. J. Virol. 80, 5875-5885 (2006)

13. Kim, J.J. et al. Modulation of antigen-specific humoral responses in rhesus macaques by using cytokine cDNAs as DNA vaccine adjuvants. J. Virol. 74, 3427-3429 (2000).

14. Sun, Y. et al. Virus-specific cellular immune correlates of survival in vaccinated monkeys after simian immunodeficiency virus challenge. J. Virol. 80, 10950-10956 (2006).
15. Buchbinder, S.P. et al. Efficacy assessment of a cell-mediated immunity HIV-1 vaccine (the Step Study): a double-blind, randomised, placebocontrolled, test-of-concept trial. Lancet 372, 1881-1893 (2008).

16. Watkins, D.I., Burton, D.R., Kallas, E.G., Moore, J.P. \& Koff, W.C. Nonhuman primate models and the failure of the Merck HIV-1 vaccine in humans. Nat. Med. 14, 617-621 (2008).

17. Masopust, D. Developing an HIV cytotoxic T-lymphocyte vaccine: issues of CD8 T-cell quantity, quality and location. J. Intern. Med. 265, 125-137 (2009).

18. Halwani, R. et al. Therapeutic vaccination with simian immunodeficiency virus (SIV)-DNA + IL-12 or IL-15 induces distinct CD8 memory subsets in SIV-infected macaques. J. Immunol. 180, 7969-7979 (2008).

19. McCoy, K. et al. Effect of preexisting immunity to adenovirus human serotype 5 antigens on the immune responses of nonhuman primates to vaccine regimens based on human- or chimpanzee-derived adenovirus vectors. J. Virol. 81, 6594-6604 (2007).

20. Hidajat, R. et al. Correlation of vaccine-elicited systemic and mucosal nonneutralizing antibody activities with reduced acute viremia following intrarectal simian immunodeficiency virus SIVmac251 challenge of rhesus macaques. J. Virol. 83, 791-801 (2009).

21. Liu, J. et al. Immune control of an SIV challenge by a T-cell-based vaccine in rhesus monkeys. Nature 457, 87-91 (2009).

22. Pal, R. et al. ALVAC-SIV-gag-pol-env-based vaccination and macaque major histocompatibility complex class I $\left(A^{*} 01\right)$ delay simian immunodeficiency virus SIVmac-induced immunodeficiency. J. Virol. 76, 292-302 (2002).

23. Zhou, Q. et al. Comparative evaluation of oral and intranasal priming with replication-competent adenovirus 5 host range mutant (Ad5hr)-simian immunodeficiency virus (SIV) recombinant vaccines on immunogenicity and protective efficacy against SIV(mac251). Vaccine $\mathbf{2 5}$, 8021-8035 (2007).

24. Brenchley, J.M. et al. CD4+ T cell depletion during all stages of HIV disease occurs predominantly in the gastrointestinal tract. J. Exp. Med. 200, 749-759 (2004).

25. Guadalupe, M. et al. Severe CD4+ T-cell depletion in gut lymphoid tissue during primary human immunodeficiency virus type 1 infection and substantial delay in restoration following highly active antiretroviral therapy. J. Virol. 77, 11708-11717 (2003).

26. Letvin, N.L. et al. Preserved CD4+ central memory T cells and survival in vaccinated SIV-challenged monkeys. Science 312, 1530-1533 (2006).

27. Mattapallil, J.J. et al. Massive infection and loss of memory CD4+ T cells in multiple tissues during acute SIV infection. Nature 434, 1093-1097 (2005).

28. Mehandru, S. et al. Mechanisms of gastrointestinal CD4+ T-cell depletion during acute and early human immunodeficiency virus type 1 infection. J. Virol. 81, 599-612 (2007).

29. Nishimura, Y. et al. Highly pathogenic SHIVs and SIVs target different $\mathrm{CD} 4+\mathrm{T}$ cell subsets in rhesus monkeys, explaining their divergent clinical courses. Proc. Natl Acad. Sci. USA 101, 12324-12329 (2004).

30. Paiardini, M., Frank, I., Pandrea, I., Apetrei, C. \& Silvestri, G. Mucosal immune dysfunction in AIDS pathogenesis. AIDS Rev. 10, 36-46 (2008).

31. Neutra, M.R. \& Kozlowski, P.A. Mucosal vaccines: the promise and the challenge. Nat. Rev. Immunol. 6, 148-158 (2006).

32. Modlin, J.F., Halsey, N.A., Thoms, M.L., Meschievitz, C.K. \& Patriarca, P.A. Humoral and mucosal immunity in infants induced by three sequential inactivated poliovirus vaccine-live attenuated oral poliovirus vaccine immunization schedules. Baltimore Area Polio Vaccine Study Group. J. Infect. Dis. 175 (Suppl 1), S228-S234 (1997).

33. Ogra, P.L. Comparative evaluation of immunization with live attenuated and inactivated poliovirus vaccines. Ann. NY Acad. Sci. 754, 97-107 (1995).

34. Mattapallil, J.J. et al. Vaccination preserves CD4 memory T cells during acute simian immunodeficiency virus challenge. J. Exp. Med. 203, 1533-1541 (2006).

35. Wang, X., Xu, H. \& Veazey, R.S. B7 integrin expression on CD4+ T cells as a surrogate marker for tracking intestinal CD4+ T cell loss in SIV infection. Keystone Symposia 2009, Prevention of AIDS (X3). Abstract 021, p 62 Keystone, Colorado, USA. March 22-27, 2009. (2009).

36. Douek, D. HIV disease progression: immune activation, microbes, and a leaky gut. Top. HIV Med. 15, 114-117 (2007).

37. Shankar, E.M. et al. Immune reconstitution inflammatory syndrome in association with HIV/AIDS and tuberculosis: views over hidden possibilities. AIDS Res. Ther. 4, 29 (2007). 


\section{ARTICLES}

38. Kozlowski, P.A., Cu-Uvin, S., Neutra, M.R. \& Flanigan, T.P. Comparison of the oral, rectal, and vaginal immunization routes for induction of antibodies in recta and genital tract secretions of women. Infect. Immun. 65, 1387-1394 (1997).

39. Moss, B. et al. Host range restricted, non-replicating vaccinia virus vectors as vaccine candidates. Adv. Exp. Med. Biol. 397, 7-13 (1996).

40. Murphy, B.R. Mucosal immunity to viruses. In Mucosal Immunology (Mestecky, J., Bienenstock, J., Lamm, M.E., Strober, W., McGhee, J.R., \& Mayer, L., eds) 799-814 (Elsevier Academic Press, Burlington, MA, 2005)

41. Crotty, S. et al. Mucosal immunization of cynomolgus macaques with two serotypes of live poliovirus vectors expressing simian immunodeficiency virus antigens: stimulation of humoral, mucosal, and cellular immunity. J. Virol. 73, 9485-9495 (1999).

42. Lamm, M.E. Current concepts in mucosal immunity. IV. How epithelial transport of IgA antibodies relates to host defense. Am. J. Physiol. 274, G614-G617 (1998).

43. Ma, Z.M., Abel, K., Rourke, T., Wang, Y. \& Miller, C.J. A period of transient viremia and occult infection precedes persistent viremia and antiviral immune responses during multiple low-dose intravaginal simian immunodeficiency virus inoculations. J. Virol. 78, 14048-14052 (2004).

44. McChesney, M.B. et al. Occult systemic infection and persistent simian immunodeficiency virus (SIV)-specific CD4(+)-T-cell proliferative responses in rhesus macaques that were transiently viremic after intravaginal inoculation of SIV. J. Virol. 72, 10029-10035 (1998).
45. Miller, C.J. et al. Intravaginal inoculation of rhesus macaques with cell-free simian immunodeficiency virus results in persistent or transient viremia. J. Virol. 68, 6391-6400 (1994).

46. Wang, S.W. et al. Effective induction of simian immunodeficiency virusspecific systemic and mucosal immune responses in primates by vaccination with proviral DNA producing intact but noninfectious virions J. Virol. 74, 10514-10522 (2000).

47. Oh, S., Berzofsky, J.A., Burke, D.S., Waldmann, T.A. \& Perera, L.P. Coadministration of HIV vaccine vectors with vaccinia viruses expressing IL-15 but not IL-2 induces long-lasting cellular immunity. Proc. Natl Acad. Sci. USA 100, 3392-3397 (2003).

48. Kozlowski, P.A. et al. Modified wick method using Weck-Cel sponges for collection of human rectal secretions and analysis of mucosal HIV antibody. J. Acquir. Immune Defic. Syndr. 24, 297-309 (2000).

49. Montefiori, D.C. Evaluating neutralizing antibodies against HIV, SIV and SHIV in luciferase reporter gene assays. In Current Protocols in Immunology (Coligan, J.E., Kruisbeek, A.M., Margulies, D.H., Shevach, E.M., Strober, W. \& Coico, R., eds) 12.11.1-12.11.15 (John Wiley \& Sons, Hoboken, NJ, 2004).

50. Lifson, J.D. et al. Role of CD8(+) lymphocytes in control of simian immunodeficiency virus infection and resistance to rechallenge after transient early antiretroviral treatment. J. Virol. 75, 10187-10199 (2001). 